Check for updates

Cite this: RSC Adv., 2019, 9, 7388

Received 12th January 2019

Accepted 25th February 2019

DOI: 10.1039/c9ra00282k

rsc.li/rsc-advances

\section{Hybrid fillers of hexagonal and cubic boron nitride in epoxy composites for thermal management applications $\uparrow$}

\begin{abstract}
Yuyuan Zhang, (D) Wei Gao, (D) Yujing Li, Dehe Zhao and Hong Yin (DD *
In this study, the synergistic effect of hexagonal boron nitride (h-BN) with cubic boron nitride (c-BN) on enhancement of thermal conductivity of epoxy resin composites has been reported. The measured thermal conductivities of the epoxy composites filled with $\mathrm{h}-\mathrm{BN}, \mathrm{c}-\mathrm{BN}$ and hybrid h-BN/c-BN compared with the theoretical predications of Agari's model strongly suggest that the combination of $h-B N$ platelets and C-BN spherical particles with different sizes is beneficial to enhance the thermal conductivity of the polymer composites by preferentially forming 3D thermally conductive networks at low loading content. Furthermore, the small addition of gold nanoparticles enhances the thermal conductivity from $166 \%$ to $237 \%$. The potential application of these composites for thermal management has been demonstrated by the surface temperature variations in real time during heating. The results demonstrate that such thermally conductive but electrically insulating polymer-based composites are highly desirable for thermal management applications.
\end{abstract}

\section{Introduction}

The rapidly increasing power density of electronic devices due to the continuous miniaturization and/or integration of electronic components and circuits, operation at high frequency and high power conditions, results in thermal management becoming a crucial issue in many related fields..$^{1-3}$ Polymerbased materials capable of efficient heat dissipation have attracted considerable attention in the field of electronic packaging because of their advantages of light weight, electrical insulation, easy manufacture and low cost. ${ }^{4-6}$ Unfortunately, the neat polymers usually exhibit poor thermal conductivity in the range of $0.1-0.4 \mathrm{~W} \mathrm{~m}^{-1} \mathrm{~K}^{-1}$.-9 Adding inorganic fillers with high thermal conductivity, such as $\mathrm{Al}_{2} \mathrm{O}_{3},{ }^{10-12} \mathrm{AlN},{ }^{13,14}$ carbon nanotubes (CNTs) ${ }^{15-17}$ graphene, ${ }^{1,18,19}$ boron nitride $(\mathrm{BN})^{2,20,21}$ etc., is believed to be an effective way to improve thermal conductivity of the polymer matrix. However, very high filler loading ( $>50 \mathrm{wt} \%)$ is generally involved in order to achieve high thermal conductivity of the polymer composites, which results in high cost, heavy weight, and the significant deterioration of mechanical integrity of the polymer materials. ${ }^{22}$

Substantial efforts, such as surface modification, ${ }^{23,24}$ alignment by electrical field and magnetic field, ${ }^{25,26}$ and the use of hybrid additives ${ }^{27-29}$ have been devoted to develop high thermal performance of the polymer composites with lower loading

State Key Lab of Superhard Materials, College of Physics, Jilin University, Changchun 130012, P. R. China. E-mail: hyin@jlu.edu.cn

$\dagger$ Electronic supplementary information (ESI) available. See DOI: $10.1039 / \mathrm{c} 9 \mathrm{ra} 00282 \mathrm{k}$ content. The simultaneous use of multi-component fillers with different morphologies, dimensions, and sizes is an alternative strategy to enhance the thermal conductivity of the composites due to their capability of formation of efficient thermal networks beneficial from the synergistic effect, ${ }^{30-32}$ For example, hybrid nanofillers of $\mathrm{CNT} / \mathrm{MoS}_{2}$ in epoxy composites have shown an improved thermal performance with loading content of only $2 \mathrm{wt} \%{ }^{33} \mathrm{Kim}$ et al. reported efficient heat transport of $\mathrm{Al}_{2} \mathrm{O}_{3}$-based polymer composites containing texturing $\mathrm{BN}$ nanoplatelet. ${ }^{12}$ Jiang et al. has proposed a hybrid filler combination of $\alpha-\mathrm{Al}_{2} \mathrm{O}_{3}$ and BN nanosheets, in which $\alpha-\mathrm{Al}_{2} \mathrm{O}_{3}$ acted as a bridge to link the $\mathrm{BN}$ nanosheets together. ${ }^{11} \mathrm{Yu}$ et al. prepared $\mathrm{BN} /$ cellulosic fibre insulating composites with an enhancement of $387 \%$ in thermal conductivity with BN loading of $41.08 \mathrm{wt} \% .^{24}$ Moreover, a high thermal conductivity of $6.71 \mathrm{~W} \mathrm{~m}^{-1} \mathrm{~K}^{-1}$ was obtained for epoxy composites consisting of $50 \mathrm{wt} \% \mathrm{Al}_{2} \mathrm{O}_{3}$ platelets and $0.6 \mathrm{wt} \%$ silver nanoparticles, in which the thermal resistance at the filler/filler interface decreased after the addition of silver nanoparticles. ${ }^{34}$ Thus, construction of threedimensional (3D) thermal conduction networks in polymeric composites is crucial for high-efficiency thermally conductivity enhancement at low filler loadings.

So far, hexagonal type of BN (h-BN) has been already proved to be a good choice as thermally conductive fillers due to its extremely high thermal conductivity, low dielectric constant, low dielectric loss and superior chemical stability. ${ }^{35,36}$ It possesses a structure analog to graphite with $\mathrm{B}$ and $\mathrm{N}$ atoms positioning alternatively forming $2 \mathrm{D}$ conjugated layers, which enables anisotropic thermal conductivity of $300 \mathrm{~W} \mathrm{~m}^{-1} \mathrm{~K}^{-1}$ along the basal plane (0002) and only several $\mathrm{W} \mathrm{m}^{-1} \mathrm{~K}^{-1}$ 
perpendicularly. ${ }^{12,37}$ Indeed, cubic type of BN (c-BN) is another crystalline form, similar to diamond, whose extremely high hardness, superb chemical inertness and thermal conductivity up to $1300 \mathrm{~W} \mathrm{~m}^{-1} \mathrm{~K}^{-1}$ make it a potential thermal conductive fillers as well. ${ }^{38,39}$ Especially, unlike those highly electrically conductive fillers, both h-BN and c-BN exhibit high electrical resistivity, making it a promising candidate as thermally conductive fillers for microelectronic device packing and thermal dissipation applications where excellent thermal dissipation and electrically insulation are exclusively required. ${ }^{40,41}$ Previous works on polymeric composites have been emphasized on the use of either h-BN particles or few layered h-BN nanosheets as the sole filler. ${ }^{42,43}$ For instance, SiR composites filled with microsized h-BN exhibited higher thermal conductivity than that filled with nanosized h-BN. ${ }^{44}$ The results showed that plate-like particles with an aspect ratio of 20 could result in the highest thermal performance. Similar result showed that h-BN nanofillers with lower than $100 \mathrm{~nm}$ failed to enhance the thermal conductivity of PI composites due to the presence of high interfacial thermal resistance at the BN/PI interfaces. ${ }^{45}$ These studies mainly discussed the effects of $\mathrm{h}$ BN with different sizes and shapes, whereas those of c-BN were rarely reported. It has been suggested that the arrangement, size and shape combinations of the hybrid filler loading form more preferential pathways for heat conduction than that of the solely h-BN fillers. ${ }^{35,39,46}$ Thus, taking these merits of BN into account, it is believed that high-thermal conductivity polymer composites can be anticipated by constructing platelike h-BN and spherical c-BN interconnected structures at low filler loading content.

Accordingly in the present work, we report a synergistic effect of $\mathrm{h}-\mathrm{BN}$ and c-BN on the enhancement of thermal conductivity of polymeric composites. Epoxy resin is chosen as the polymer matrix, whose thermal conductivity is $0.19 \mathrm{~W} \mathrm{~m}^{-1} \mathrm{~K}^{-1}$. The thermal conductivity is enhanced up to $166 \%$ for the EP composites containing hybrid fillers of $4.2 \mathrm{vol} \% \mathrm{~h}$-BN platelets and $6.2 \mathrm{vol} \% \mathrm{c}-\mathrm{BN}$ spherical particles. Additionally, further improvement of $237 \%$ in the thermal conductivity of h-BN/cBN/EP composites is achieved by adding small amount of gold nanoparticles, which can be ascribed to enhanced interconnectivity between BN fillers. These composites have demonstrated improve thermal conductivity and excellent electrical insulation, thus promising for heat dissipation materials and microelectronic packing materials in the future electronic device.

\section{Experimental}

\subsection{Materials}

Plate-like h-BN powders with purity of $99.5 \%$ were purchased from Alfa Aesar (Germany) Chemicals Co., Ltd. and c-BN spherical particles with purity of $99 \%$ were purchased from Funik Ultra Hard Material Co., Ltd (China). Epoxy resin and curing agent were provided from Nantong Xingchen Synthetic Material Co., Ltd (China). Silane coupling agent KH-550 (density 0.94-0.95 $\mathrm{g} \mathrm{mL}^{-1}$ at $20{ }^{\circ} \mathrm{C}$ ) was obtained from Sinopharm Chemical Reagent Co., Ltd (China). Hydrogen
tetrachloroaurate(III)hydrate, Premion, 99.999\% (metals basis), $\mathrm{Au} 49 \%$ min were purchased from Alfa Aesar (Germany) Chemicals Co., Ltd. Toluene was obtained from Beijing Chemical Works (China).

\subsection{Surface modification of fillers}

The pristine $\mathrm{BN}$ powder was first thermally treated under air to produce -OH group on the surface. ${ }^{21} \mathrm{~h}-\mathrm{BN}$ powder was placed in a quartz tube in a tube furnace and it was heated up to $1000^{\circ} \mathrm{C}$ at a rate of $10{ }^{\circ} \mathrm{C}$ per minute and maintained at that temperature for $2 \mathrm{~h}$. For c-BN spherical particles, the tube furnace was heated up to $750{ }^{\circ} \mathrm{C}$ at a rate of $10^{\circ} \mathrm{C}$ per minute and maintained for $750{ }^{\circ} \mathrm{C}$ for $1 \mathrm{~h}$. Then, the furnace was cooled down naturally to room temperature, and the product was collected.

The further surface treatment by KH-550 of BN can be found elsewhere. ${ }^{47}$ The content of $\mathrm{KH}-550$ is $5 \%$ according to the weight of BN powder after thermal treatment. KH-550 was slowly dropped into the solvent of ethanol and water mixture, and stirred for $20 \mathrm{~min}$. The BN powder was added to the solution for $15 \mathrm{~min}$, and was stirred magnetically for $2 \mathrm{~h}$ at $60{ }^{\circ} \mathrm{C}$. Then the solution was cooled down to room temperature, filtered in vacuum and cleaned with ethanol to remove the excess $\mathrm{KH}-550$. The final product was dried at $100{ }^{\circ} \mathrm{C}$ for $12 \mathrm{~h}$ in vacuum.

\subsection{Preparation of Au-h-BN fillers}

Au NPs were prepared using a micellar approach, the final result was an array of well-separated pure Au NPs of rather uniform size. ${ }^{48}$ The preparation of the surface decoration of h-BN platelets by $\mathrm{Au}$ NPs follows the following steps. First, the modified h-BN platelets $(1 \mathrm{~g})$ were added into the Au salt preloaded micellar solution $(5 \mathrm{~mL})$. Then, this solution was stirred for $60 \mathrm{~min}$ at ambient conditions to promote interaction of gold ions with the functionalized h-BN platelets. Finally, the mixture was annealed at $100{ }^{\circ} \mathrm{C}$ for $12 \mathrm{~h}$ to obtain $\mathrm{Au}-\mathrm{h}$-BN fillers.

\subsection{Preparation of composite materials}

The epoxy resin E-44 and fillers with varied weight fractions were mixed using ethanol as solvent, then treated by ultrasonic for $30 \mathrm{~min}$ at room temperature. Afterwards, the curing agent (650) (1:1 mass ratio to epoxy resin) was dropped into the mixture, stirred manually. The as-obtained slurry was then degassed under vacuum for $30 \mathrm{~min}$. Then, the composite was poured into the mold, and solidified firstly at room temperature for $3 \mathrm{~h}$ and further at $80^{\circ} \mathrm{C}$ for another $4 \mathrm{~h}$ in an oven. Finally, the composite was naturally cooled down to room temperature and then peeled. The whole preparation process of BN/epoxy composites and surface modification of BN fillers are illustrated in Scheme 1.

\subsection{Characterization}

The microstructure and morphology of the composites were observed by scanning electron microscope (SEM, Philips FEI Quanta Magellan 400). Fourier transform infrared (FTIR) analysis was performed on an IRAffinity-1 spectrophotometer. 


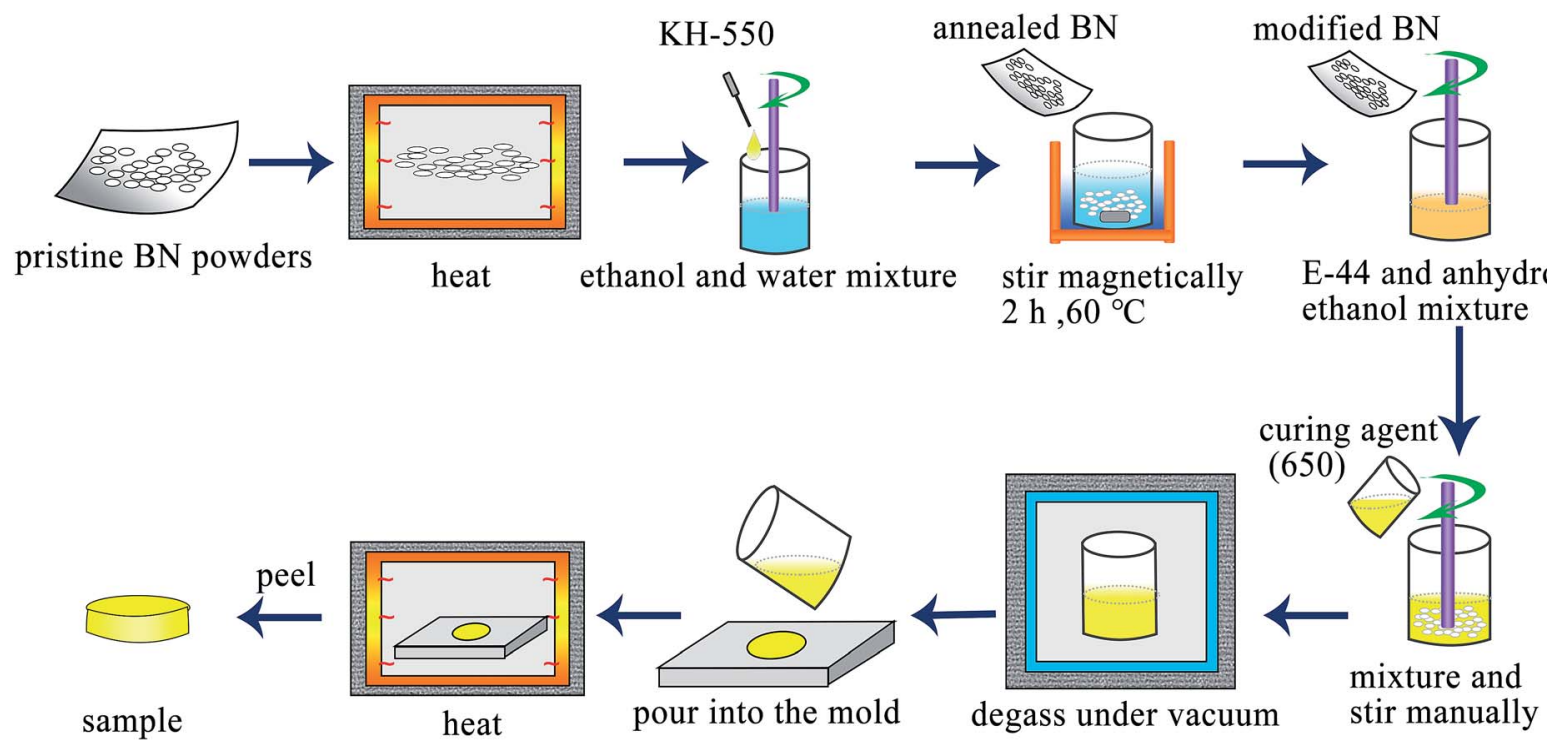

Scheme 1 Schematic illustration of the preparation progress of BN/epoxy composites and surface modification of BN.

Raman spectrum was obtained over the range $1300-1450 \mathrm{~cm}^{-1}$ on a Renishaw Invia Raman Microscope with a $514 \mathrm{~nm}$ argon ion laser. X-ray photoelectron spectroscopy (XPS) was conducted using a Thermo ESCALAB 250, operating at Al-K $\alpha$ radiation $(h \nu=1486.6 \mathrm{eV})$ with detecting chamber pressure of $2.6 \times 10^{-9}$ mbar. X-ray diffraction (XRD) patterns of samples were performed on a Bruker D8 diffractometer using a $\mathrm{Cu}$ radiation $(\lambda=$ $0.1542 \mathrm{~nm}$ ). Transmission electron microscopy (TEM) images were recorded using a JEOL JEM-2200FS instrument with an acceleration voltage of $200 \mathrm{kV}$. The through plane thermal conductivity (TC), $\lambda$, is calculated by the following equation:

$$
\lambda=\alpha C_{\mathrm{p}} \rho
$$

where $\alpha, C_{\mathrm{p}}$, and $\rho$ are thermal diffusivity, heat capacity, and density of the sample, respectively. $\alpha$ of the composite was measured by a non-contact laser flash method using a LFA 1000 (Linseis) at $40{ }^{\circ} \mathrm{C}$. The geometric shape of the sample is cylindrical, with a diameter of $10 \mathrm{~mm}$ and a thickness of $3 \mathrm{~mm}$. The $C_{\mathrm{p}}$ was measured with a calorimeter (TA Instruments Q2000) at $40{ }^{\circ} \mathrm{C}$, by means of differential scanning calorimetry (DSC). Density is measured by AE124J electronic balance (Shanghai Shunyu Hengping Scientific Instruments Co., Ltd). Sample insulation is tested using the semiconductor performance analysis system Keithley 4200. The thermal transfer capability of these composites in the real case was tested by Infrared Camera (Image IR 8300, Infra Tec GmbH, Dresden). All of the thermal measurements were performed more than three times and the average was taken for the calculation.

\section{Results and discussion}

\subsection{Surface modification of fillers}

In order to improve the dispersion and interfacial behavior between the inorganic fillers and the polymer matrix, hydroxyl $(-\mathrm{OH})$ groups were first introduced onto the surface of h-BN by heating the pristine powders at $1000{ }^{\circ} \mathrm{C}$ in air, then covalently bonded with silane coupling agent (KH-550) as illustrated in Scheme 1 . The h-BN after modified by $\mathrm{KH}-550$ remains stable in DI water and ethanol for more than 12 hours irrespective of the poor dispersion of h-BN pristine powder (Fig. S1 in $\mathrm{ESI} \dagger$ ). Moreover, SEM images of pristine h-BN present irregular platelike structures stacked on each other with smooth surfaces and edges as shown in Fig. 1a. After thermal treatment, the samples show reduced thickness and lateral length with rough and folding edges (Fig. 1b), indicating that large amount of h-BN platelets were exfoliated to some extent and the surface of h$\mathrm{BN}$ platelets has been grafted with $-\mathrm{OH}$ groups. Fig. 1c suggests that after further $\mathrm{KH}-550$ modification, h-BN platelets remains the similar geometric shapes and sizes (Fig. S2 in ESI $\dagger$ ). However, a number of tiny wrinkles over entire surface have been observed resulting from the formation of surface functional groups including hydroxyl groups, amino groups and alkyl groups due to the surface modification. The modification process is further proved by FTIR, XRD and XPS results, as shown in Fig. 2.

Fig. 2a displays the IR spectra of pristine h-BN, annealed h$\mathrm{BN}$ and modified h-BN, respectively. All spectra exhibit two strong absorption peaks at $1372 \mathrm{~cm}^{-1}$ and at $817 \mathrm{~cm}^{-1}$, corresponding to in-plane B-N stretching vibration and out-of-plane $\mathrm{B}-\mathrm{N}-\mathrm{B}$ bending vibration, respectively. ${ }^{23}$ After thermal treatment, the infrared spectrum of h-BN reveals a broad peak at $3220 \mathrm{~cm}^{-1}$, ascribing to $-\mathrm{OH}$ stretching vibration, ${ }^{21}$ which is the reactive group enabling chemical bonding between $\mathrm{BN}$ and the coupling agent. Besides, a new bending mode is trivial but noticeable at around $1200 \mathrm{~cm}^{-1}$, correlating with $\mathrm{H}_{3} \mathrm{BO}_{3}$, in which boron is triangularly coordinated with oxygen. ${ }^{49}$ For the agent modified h-BN, an additional absorption peak appears near $2900 \mathrm{~cm}^{-1}$ conforming to the characteristic peak of $-\mathrm{CH}_{2}-$ stretching vibrations from KH-550. The peak at about 1050$1100 \mathrm{~cm}^{-1}$ strongly implies the presence of anti-symmetric stretching vibration of $\mathrm{Si}-\mathrm{O}-\mathrm{Si}$ and $\mathrm{Si}-\mathrm{O}-\mathrm{C}$, resulting from the 

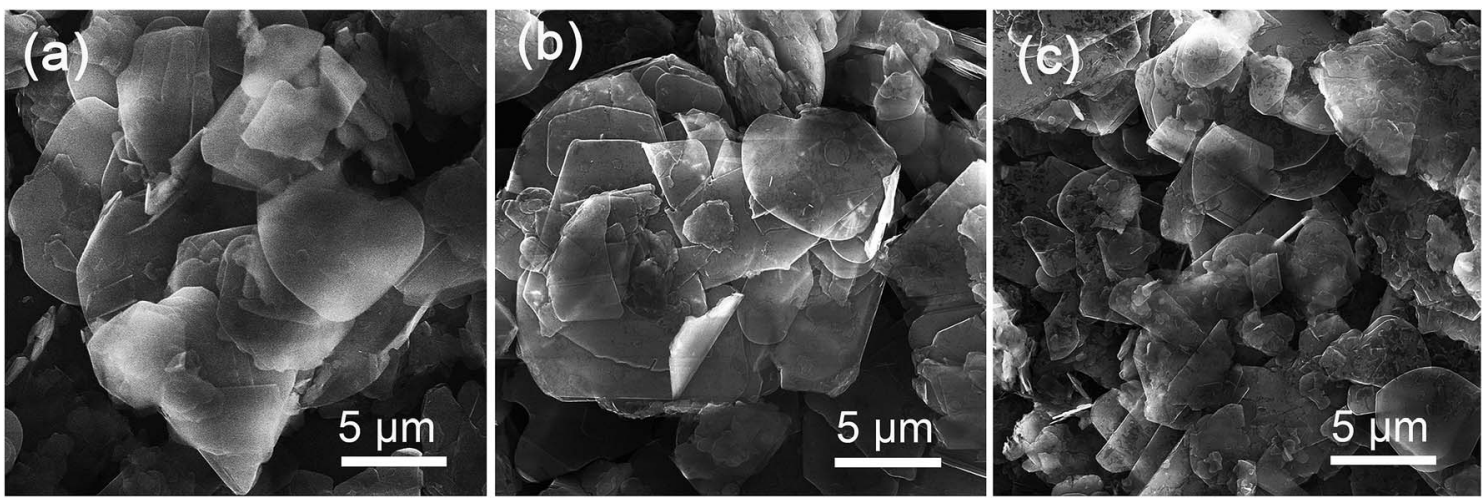

Fig. 1 SEM images of pristine (a), annealed (b) and modified h-BN (c), respectively.
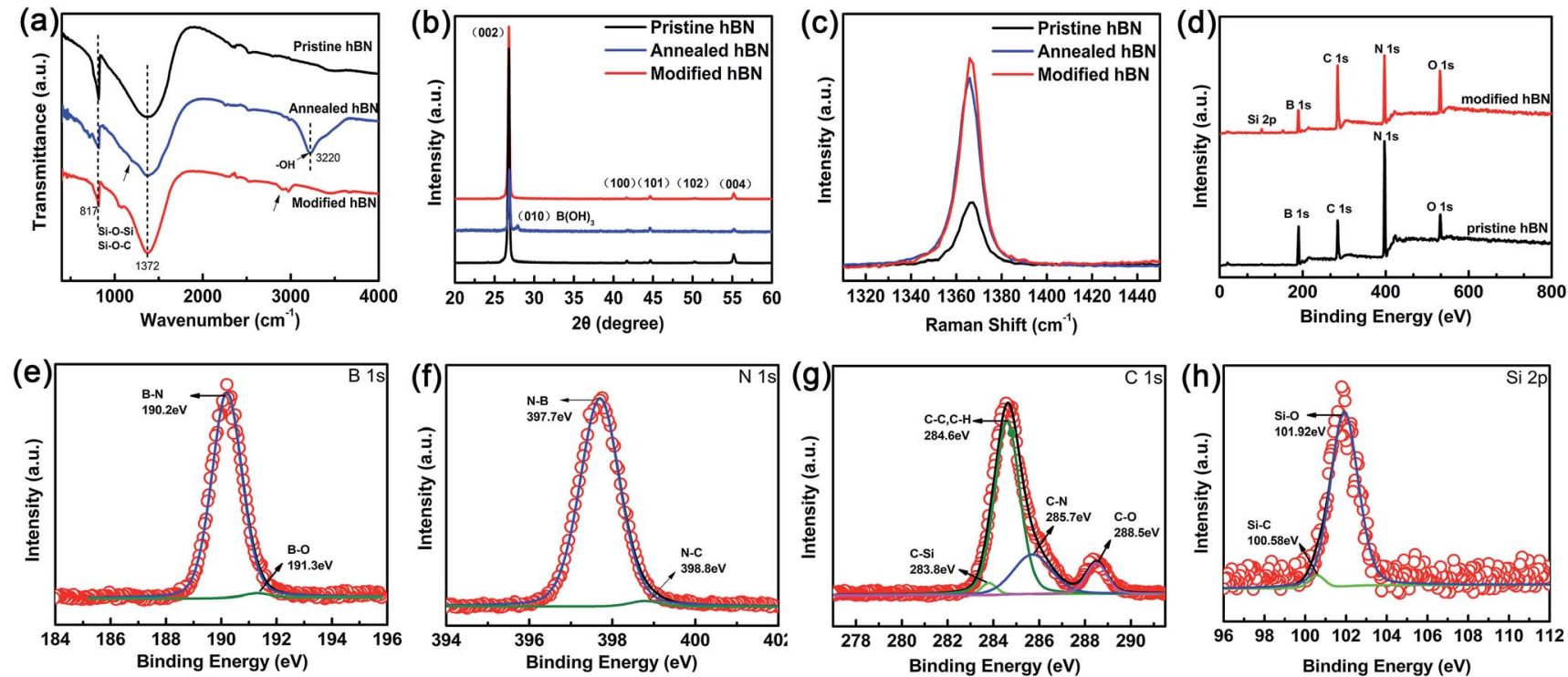

Fig. 2 FTIR spectra (a), XRD pattern (b) and Raman spectra (c) of pristine h-BN, annealed h-BN and modified h-BN, respectively. XPS survey spectra (d) of pristine and modified h-BN as well as core level peaks of B 1s (e), N 1s (f), C 1s (g), and Si $2 p$ (h) for the modified h-BN.

reaction between the hydroxylated h-BN platelets and the silane surfactant. ${ }^{24}$

XRD measurements reveal a highly ordered crystalline structure for all the h-BN samples before and after surface modification (Fig. 2b). From the Joint Committee on Powder Diffraction Standards (JCPDS no. 85-1068) for h-BN platelets of $a=b=0.2504 \mathrm{~nm}$ and $c=0.6656 \mathrm{~nm}$, all the diffraction peaks are readily indexed to be (002), (100), (101), (102) and (004). More importantly, a distinct diffraction peak at $27.9^{\circ}$ associated with $(010) \mathrm{B}(\mathrm{OH})_{3}$ is clearly visible for the h-BN platelets after thermal treatment, confirming the previous FTIR results. Furthermore, the following surface modification by $\mathrm{KH}-550$ leaves no $\mathrm{H}_{3} \mathrm{BO}_{3}$ in the final product. The Raman spectra (Fig. 2c) show a unique $\mathrm{E}_{2 \mathrm{~g}}$ mode vibration peak for all the h-BN samples. The thermal treated h-BN platelets exhibit a slight redshift of $\sim 2 \mathrm{~cm}^{-1}$ regarding to the pristine h-BN platelets, again implying the reduction of flake thickness due to heating process.
In conjugation with FTIR, XPS investigation has been validating the surface composition and the functional groups of $h$ $\mathrm{BN}$ after modification (Fig. $2 \mathrm{~d}-\mathrm{h}$, Table S1 in ESI $\dagger$ ). The binding energy was calibrated with reference to the C 1s energy as $284.5 \mathrm{eV}$. When compared to the pristine powder, the XPS survey spectrum (Fig. 2d) of h-BN after surface modification displays four similar peaks of B 1s, N 1s, C 1s, and $\mathrm{O} 1 \mathrm{~s}$ at approximately 190.2, 397.7, 284.6, and $531.9 \mathrm{eV}$, but with different percentages. The enhancement of $\mathrm{C} 1 \mathrm{~s}$ and $\mathrm{O} 1 \mathrm{~s}$ implies the successful attachment of the silane coupling agent on the surfaces and the edges of h-BN, which is further evident by the emerge of Si $2 \mathrm{p}$ at $101.9 \mathrm{eV}$ for the modified sample.

The chemical bonding of the modified h-BN is further confirmed by B 1s, N 1s, C 1s and Si 2p core level spectra together with their corresponding de-convolutions in a more detailed description as demonstrated in Fig. 2e-h. In addition to the strong $\mathrm{B}-\mathrm{N}$ bond in $\mathrm{B} 1 \mathrm{~s}$ and $\mathrm{N}$ 1s core level spectra clearly attributed to h-BN, the extra weak $\mathrm{C}-\mathrm{N}$ component in $\mathrm{N} 1 \mathrm{~s}$ and 
B-O component in B 1s are fitted at $398.8 \mathrm{eV}$ and $191.3 \mathrm{eV}$, respectively. The former is from the contribution of surface agents, however the latter is evidencing that $\mathrm{B}$ is the only reactive site for the silane coupling agents through hydroxyl groups on the BN surfaces. Furthermore, the strong $\mathrm{C}-\mathrm{C}$ and $\mathrm{C}-\mathrm{H}$ peaks, the weak $\mathrm{C}-\mathrm{N}, \mathrm{C}-\mathrm{O}$ and $\mathrm{C}-\mathrm{Si}$ in $\mathrm{C}$ 1s core level spectrum as well as $\mathrm{Si}-\mathrm{O}$ and $\mathrm{Si}-\mathrm{C}$ bonds are present in the structure of the silane coupling agent, indicating that the surfaces and edges of h-BN are successfully grated by the silane coupler. Therefore, the above results clearly suggest that the silane coupling agent has been chemically grafted on the surface (and/or edges) of h-BN through B-site with enhanced its dispersion and not descrying the crystal quality.

\section{$3.2 \mathrm{~h}-\mathrm{BN} / \mathrm{EP}$ composite materials}

Fig. 3 represents the cross-sectional morphology of the neat EP and EP composites filled with pristine and silane modified h-BN platelets with different loading content. Fig. 3a is a schematic illustration of the typical polymeric composite arrangement for thermal conductivity measurement and the cross-section of SEM test. The fractured surface of neat EP is very smooth in (a)

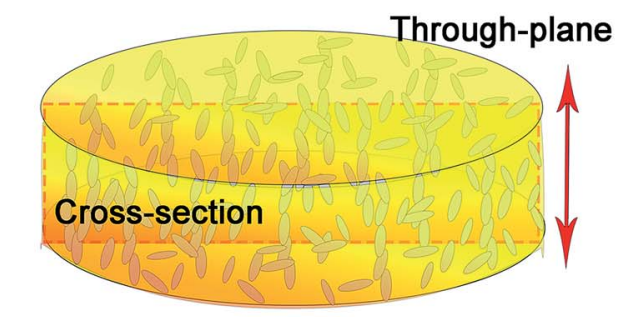

(b)
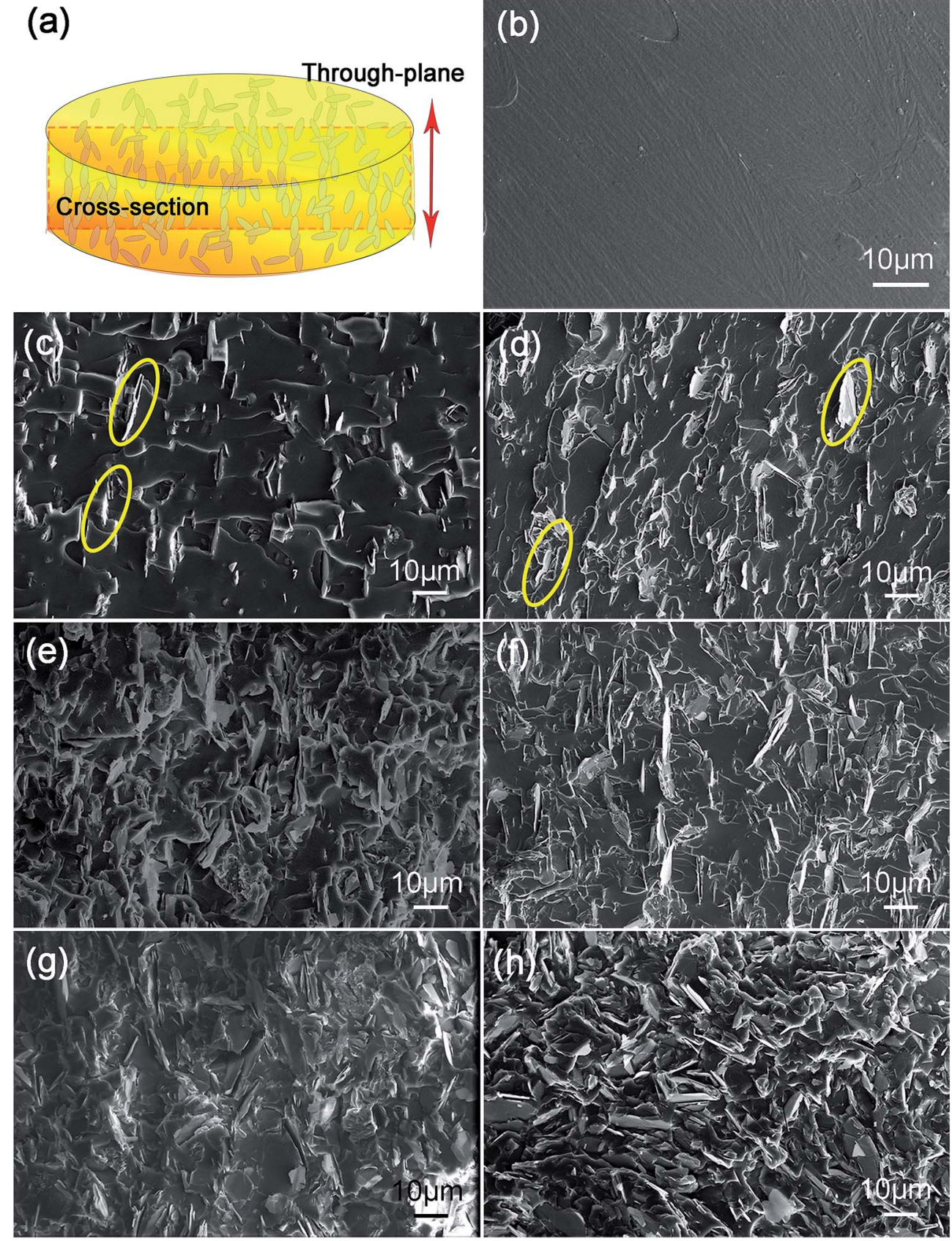

Fig. 3 (a) Schematic illustration of the composites. SEM images of cross-sectional morphology of the neat EP (b) and EP composites containing 3 vol\% (c), 6 vol\% (e), and 9 vol\% (g) pristine h-BN and 3 vol\% (d), 6 vol\% (f) and 9 vol\% (h) modified h-BN comparably. 
Fig. 3b. The fractured surfaces of EP composites become rougher as the filling content increases from 3 to 9 vol\% for both types of h-BN platelets. When the filler loading is low ( 3 vol\%), the morphology of the composite consists of isolated and randomly distributed h-BN platelets along with pores in micrometer scale marked by yellow (Fig. 3c and d). As the filler loading content increases, agglomeration phenomenon occurs for the pristine h-BN platelets due to the poor interfacial compatibility between inorganic h-BN and polymer EP matrix (Fig. 3g). Comparatively, after surface modification, densely packed h-BN platelets relatively homogeneously disperse within the matrix with much less pores (Fig. 3h). This is due to the fact that silane coupling agent grafted on the surface of h-BN platelets enhances the interfacial interaction between h-BN platelets and the EP matrix. Thus, one can predict that the improved dispersion of h-BN in EP matrix will benefit to the thermal conductivity of EP composites.

Thermal conductivity and diffusivity of the fabricated EP composites containing different h-BN loading content are shown in Fig. 4a. The thermal conductivity increases with the increasing content of h-BN in good accord with theoretical predictions. ${ }^{50}$ One can see that surface modification process of h-BN results in an enhanced thermal conductivity of the EP composites in comparison with the pristine h-BN. This is due to the silane agent attachment on the surface of h-BN, acting as phonon transfer bridges between hydoxylized h-BN and EP matrix. The strong covalent bonds between modified h-BN and EP matrix improve interfacial compatibility. The thermal conductivity of neat epoxy resin is only about $0.195 \mathrm{~W} \mathrm{~m}^{-1} \mathrm{~K}^{-1}$ at room temperature because of its amorphous nature. The low thermal conductivity at $3 \mathrm{vol} \%$ of h-BN platelets is attributed to absence of direct contact with each other, leading to higher interface thermal resistance between h-BN platelets inside composites. When the loading content increases, the h-BN platelets start to contact with each other, consequently forming continuous thermal conductive pathways or network. Therefore, the EP containing modified h-BN platelets at loading content of 9 vol\% exhibits a thermal conductivity of $0.44 \mathrm{~W} \mathrm{~m}^{-1}$ $\mathrm{K}^{-1}$, which is about 2.3 times higher than that of neat EP.
The thermal conductivities of the composites were predicted by Agari's model shown in Fig. 4a, which is a classic model for estimating the thermal conductivity of particulate composites:

$\log \lambda=V\left(X_{2} C_{2} \log \lambda_{2}+X_{3} C_{3} \log \lambda_{3}+\ldots\right)+(1-V) \log \left(C_{1} \lambda_{1}\right)(2)$

where $\lambda$ is the thermal conductivity of composites, and $\lambda_{1}, \lambda_{2}$ and $\lambda_{3}$ are the thermal conductivity of polymer matrix, the component fillers 1 and the component fillers 2, respectively; where $V=V_{2}+V_{3}+\ldots, X_{2}+X_{3}+\ldots=1, V_{1}=1-V, V$ is the total content of particles, and $X_{2}$ and $X_{3}$ are mixing ratios of fillers. $C_{1}$ is a measure of the impact of filler on the secondary structure of polymer matrix, such as crystallinity and crystal size, and can be considered to be 1 in this work. $C_{2}$ and $C_{3}$ measure how easily the filler can form conductive chains. ${ }^{51}$

In case of h-BN being the singular filler in EP matrix here, $\lambda_{1}$ and $\lambda_{2}$ are 0.194 and $300 \mathrm{~W} \mathrm{~m}^{-1} \mathrm{~K}^{-1}$, respectively. As shown in Fig. 4a, the Agari's model predicts the thermal conductivity very well. $C_{2}$ is calculated to be 0.923 and 1.298 for the EP composites containing pristine and silane coupling agent treated h-BN platelets, respectively. A higher value of $C_{2}$ indicates that the modified h-BN platelets are easier to form conductive chains other than the pristine ones in the EP composites.

This is further confirmed by the porosity analysis of the composites, in which the porosity area ratio of the sample section is calculated through the SEM cross-section images. As shown in Fig. 4b, the EP composites containing modified h-BN platelets exhibit depressed porosity compared with that containing pristine ones in the range from 3 to 9 vol\%. The crakes and pores inside the composites are considered to be major block to the heat transfer. In the case of modified h-BN, silane couplers link one end to hydroxylized surfaces and edges of hBN platelets, and the other end to EP chains, therefore binding densely to the matrix and reducing the cracks and pores.

\section{3 h-BN/c-BN/EP composite materials}

Based on the aforementioned, thermal transport of the h-BN/EP composites can be clearly enhanced by surface modification of (a)

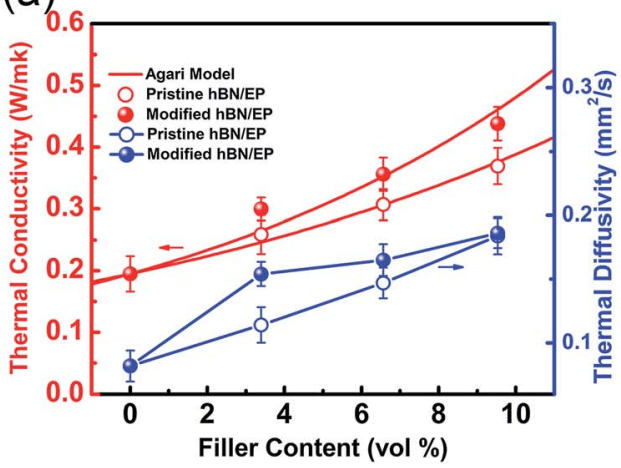

(b)

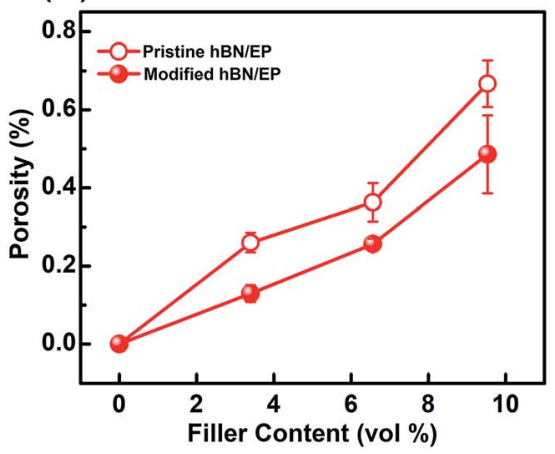

Fig. 4 (a) Thermal conductivity and diffusivity of composite containing pristine and modified h-BN as function of filler loading content, as well as the corresponding theoretical predictions of thermal conductivity based on Agari's model. (b) Depressed porosity of EP composites containing pristine and modified $\mathrm{h}-\mathrm{BN}$ as function of filler loading content, respectively. 
(a)

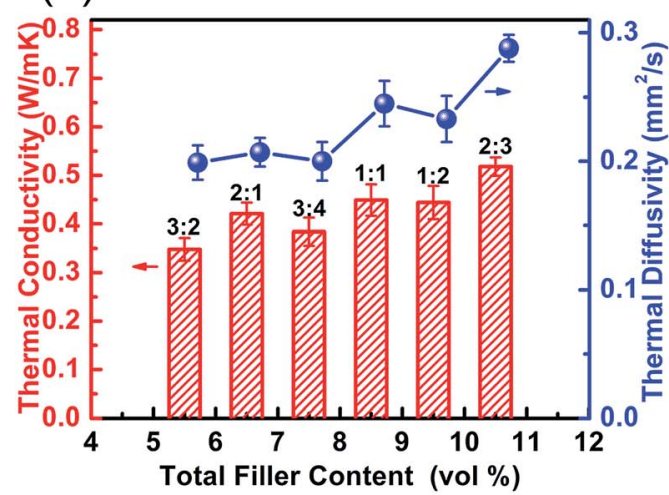

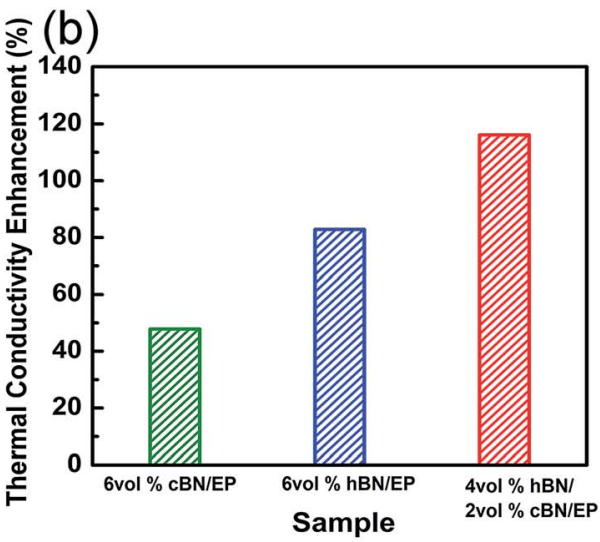

Fig. 5 (a) Thermal conductivity and thermal diffusivity of the h-BN/c-BN/EP composites at different total filler content. (b) At 6 vol\% total filler loading, thermal conductivity enhancement of c-BN/EP, h-BN/EP and h-BN/c-BN/EP composites, respectively.

h-BN platelets. However, the enhancement is limited at such low volume fractions since the interconnectivity between h-BN platelets is still not optimized. One solution is to use hybrid fillers with different sizes and different shapes to improve the interconnectivity in the polymer composites through connecting these isolated h-BN platelets. Therefore, c-BN spherical particles with diameter of $59 \mu \mathrm{m}$ are simultaneously mixed into the h-BN/EP composites, aiming to build up a skeleton to support the small h-BN platelets forming a percolation network within EP matrix. In order to improve the compatibility of c-BN within the EP matrix, the similar surface modification has been executed, resulting into chemical bonding between silane coupling agent and $\mathrm{OH}$-modified c-BN surface (Fig. S3 and Table S2 in ESI $\dagger$ ).

Fig. 5a shows the thermal conductivity and thermal diffusivity of the h-BN/c-BN/EP composites with different h-BN/c-BN volume fractions with respect to the total $\mathrm{BN}$ filler volume content (h-BN + c-BN) along the through-plane direction. Both thermal conductivity and thermal diffusivity increase as the amount of BN fillers increases from 5.5 to $10.5 \%$ in the overall trend. However, the actual values of thermal conductivity and thermal diffusivity drop down in particular regions of total filler content. For instance, the thermal conductivity is $0.421 \mathrm{~W} \mathrm{~m}^{-1}$ $\mathrm{K}^{-1}$ for the EP composites containing $6.5 \mathrm{vol} \% \mathrm{BN}$ filler (h-BN/c$\mathrm{BN}=2: 1$ ), but an unexpectedly low thermal conductivity value of $0.384 \mathrm{~W} \mathrm{~m}^{-1} \mathrm{~K}^{-1}$ is obtained for the EP composites containing $7.5 \mathrm{vol} \% \mathrm{BN}$ filler (h-BN/c-BN $=3: 4$ ). This may contradict the theoretical predictions in which the thermal conductivity would increase monotonically with increasing filler content. ${ }^{52}$ Instead, it further suggests that besides the incorporated filler content as well as the geometric factors, the volume fraction of the binary fillers may play alternative important roles in improving thermal conductivity. As clearly shown in Fig. 5b, the thermal conductivity of c-BN/EP, h-BN/EP and h-BN/c-BN/EP composites have been increased by $47.84 \%$, $82.8 \%$ and $116.14 \%$ at the same total filler loading of $6 \mathrm{vol} \%$. Explicitly, the h-BN/c-BN/EP composites exhibit the highest thermal conductivity, in which the h-BN content is 4 vol\% and the c-BN content is $2 \mathrm{vol} \%$.
According to the idealized packing density of a binary mixture derived by Furnas, ${ }^{53}$ the highest maximum packing density can be obtained when the volume ratio of large particles to small particles is $7: 3$. Previous investigation on $\mathrm{AlN} / \mathrm{BN}$ hybrid system demonstrated that the obtained measured thermal conductivity depends on the particle size and the relative volume ratio of AlN to $\mathrm{BN} .{ }^{13}$ In present case, the particle size of smaller h-BN platelets is determined to be approximately $1 / 10$ of that of larger c-BN to achieve a maximum packing density for randomly packed particles. ${ }^{54}$ Thus, Agari's model has been utilized to fit the experimental data of thermal conductivity to determine the constants $C_{2}$ and $C_{3}$, in hybrid system. Here, $C_{2}$ and $C_{3}$ describe the formation of conductive paths for h-BN and c-BN in the composite, respectively. The thermal conductivity data measured for h-BN/c-BN/EP composites fitted using Agari's model is shown in Fig. 6. As it

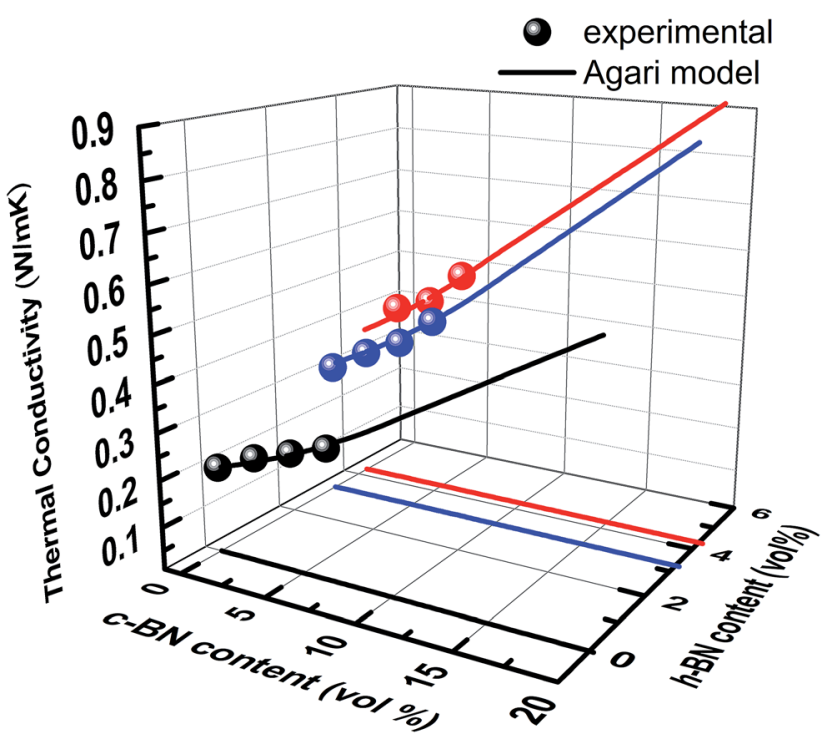

Fig. 6 Thermal conductivity of hybrid fillers h-BN/c-BN and sole filler of $c-B N$ in EP composites as function of $h-B N$ and $c-B N$ loading content, respectively. The solid lines are theoretical predications based on Agari's model. 
Table 1 Parameters $\left(C_{2}\right)$ calculated from Agari's model for h-BN/EP, c-BN/EP, and h-BN/c-BN/EP composites

\section{$C_{2}$ for}

different filler

system

h-BN

c-BN

Sole filler

Hybrid fillers

1.2976

2.1929

0.658

0.5854

can be observed, the Agari's model agrees with the experimental data very well. The parameters obtained are collected in Table 1.

For the EP composites containing single filler type, h-BN platelets have a higher $C_{2}$ coefficient than c-BN, and thermal conductivity is higher for the same amount of filler content. It is worth noting that for the EP composites containing hybrid filler type, $C_{2}$ for h-BN is significantly higher than that for c-BN. This strongly suggests that the small h-BN platelets prefer to form very efficient conductive paths when compare to the large c-BN spherical particles. This consequently explains the fluctuation of thermal conductivity values in Fig. 5a. In the case of h-BN/c$\mathrm{BN}$ volume ratio smaller than 1 , it is difficult for large c-BN spherical particles to connect with each other even with the higher volume content, resulting in a low thermal conductivity irrespective of the extremely high thermal conductivity of c-BN itself. As a matter of fact, when h-BN/c-BN volume ratio is bigger than 1, the thermal conductivity of the EP composites significantly increases, which is attributed to the more thermal networks formed by plate-like h-BN surrounding the large c-BN spherical particles. This is further evident by cross-sectional SEM images as shown in Fig. 7.

Fig. 7a and b illustrate the cross-sectional morphology of the h-BN/c-BN/EP composites filled with h-BN/c-BN of $3: 4$ (total filler content $7.5 \mathrm{vol} \%$ ) and of $2: 1$ (total filler content $6.5 \mathrm{vol} \%$ ), respectively. It can be clearly observed that the small h-BN platelets are located in the sparse interstitial spaces formed by large c-BN spherical particles within the EP matrix when the volume fraction of h-BN/c-BN is $3: 4$ as observed in Fig. 7a. The layered structures of h-BN platelets disperse separately within the polymer matrix without connecting with other h-BN platelets or with large c-BN spherical particles, mainly remaining the morphology of EP composites with single h-BN component. Furthermore, the zoom-in zones marked in Fig. 7a show distinct holes and cracks among interfacial boundaries as seen in Fig. 7c. As a result, heat transfer cannot effectively occur through BN fillers to nearby fillers. On the other hand, in Fig. 7b, the plate-like small h-BN platelets are homogeneously distributed within the matrix, preferring to surround the large c-BN spherical particles when the volume fraction of h-BN/c-BN is $2: 1$. As compared to Fig. 7a, the EP composites containing higher h-BN platelets volume fraction over c-BN exhibit much less narrow holes and gaps, indicating that in this case large cBN spherical particles form very efficient conductive paths when surrounded by substantial h-BN platelets. This may explain the higher $C_{2}$ constant obtained for small h-BN platelets over extremely low value for large c-BN spherical particles from
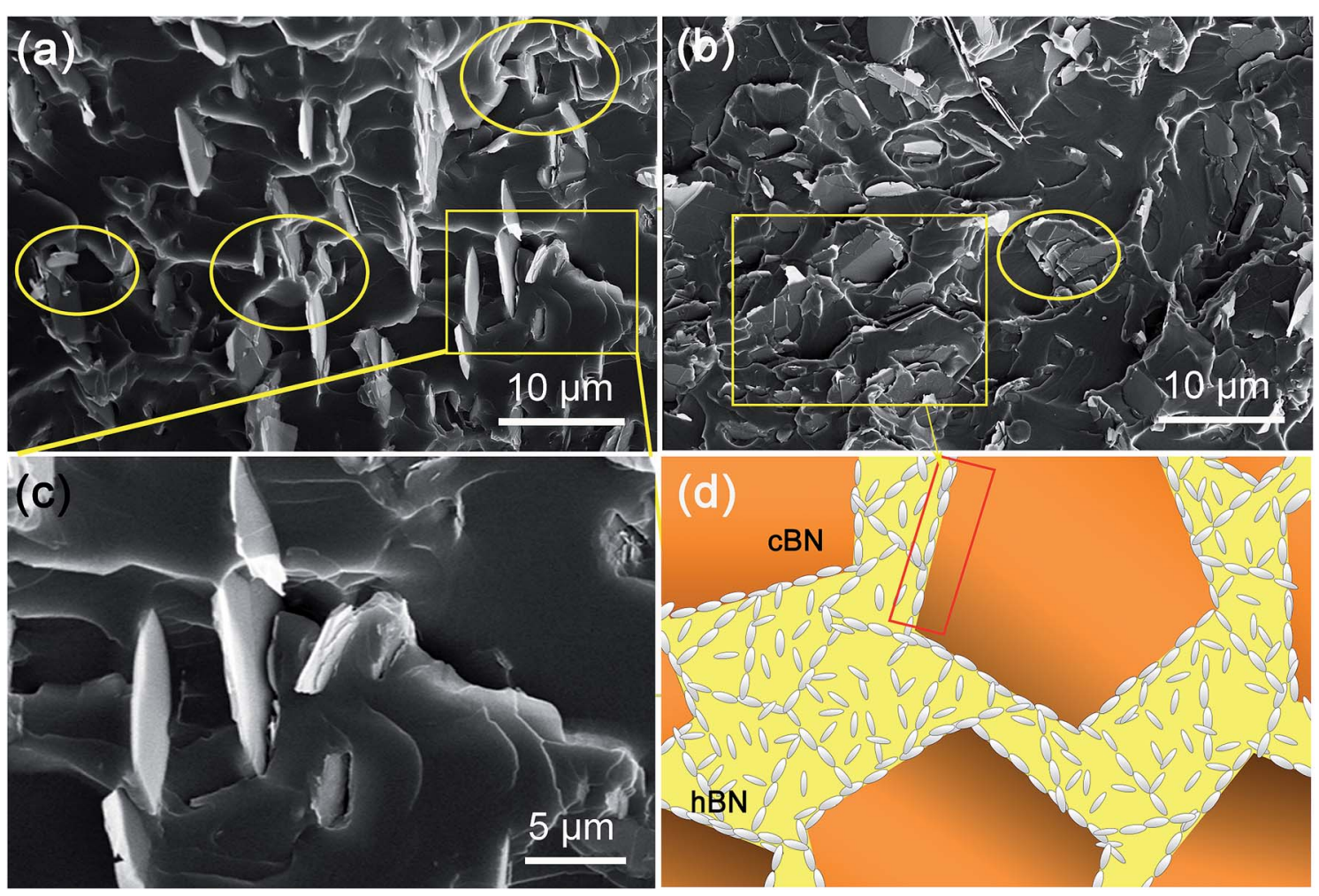

Fig. 7 SEM images of the cross-sectional morphology for $h-B N / c-B N / E P$ composites containing h-BN/c-BN hybrid fillers of $3: 4$ (a) and $2: 1$ (b). (c) Magnification of the selected rectangular region in (a). (d) Schematic representations for ideal model structures for h-BN/c-BN hybrid fillers arranged within the EP matrix. 
the Agari's model fitting. The introduction of higher volume fraction of h-BN platelets into the large c-BN filled EP matrix creates additional contacts between c-BN particles in comparison to the singly $\mathrm{BN}$ filled systems, resulting into the formation of 3D-thermal networks (Fig. 7d).

\subsection{Au-h-BN/c-BN/EP composite materials}

Furthermore, it has been found that the additional introduction of Ag nanoparticles into polymer matrix can effectively affect the thermal properties of $\mathrm{Al}_{2} \mathrm{O}_{3}$ /epoxy composites. ${ }^{34}$ This is due to that the addition of small spherical particles into a platelets contained colloidal system can mediate depletion attraction between platelets. ${ }^{55}$ Here, Au NPs have been added into h-BN/c$\mathrm{BN} / \mathrm{EP}$ composites, expecting to further improve the thermal properties thereby strengthening the interfacial contacts between BN fillers. The fabrication procedure of $\mathrm{Au}-\mathrm{h}-\mathrm{BN} / \mathrm{c}-\mathrm{BN} /$ EP composites includes the surface decoration of h-BN platelets by $\mathrm{Au}$ NPs and the Au-h-BN/c-BN/EP composites prepared as depicted in Fig. 1. The difference is that the filler added is a certain proportion of $\mathrm{Au}-\mathrm{h}-\mathrm{BN}$ and modified c-BN. Fig. 8a and b show the TEM images of the surface modified h-BN platelets before and after Au NPs decoration, respectively. The presence of Au NPs with a size of $9 \mathrm{~nm}$ on the surfaces of h-BN platelets can be clearly observed in Fig. 8b. Moreover, the majority of $\mathrm{Au}$ NPs preferentially congest at the edges of h-BN platelets as marked by red circle. The color of h-BN platelets solution has changed from white to yellow after the decoration of Au NPs, as seen in inset. Fig. 8c represents a typical zoom-in zone of Fig. $8 \mathrm{~b}$, in which the interplanar spacing of the Au NPs lattice is approximately $0.21 \mathrm{~nm}$, attributed to the (111) plane. Fig. $8 \mathrm{~d}$ represents the as-prepared $\mathrm{Au}-\mathrm{h}-\mathrm{BN} / \mathrm{c}-\mathrm{BN} / \mathrm{EP}$ composites containing 3 vol\% h-BN and 6 vol\% c-BN. As the Au NPs are much smaller than h-BN platelets and c-BN particles, it is difficult to distinguish $\mathrm{Au}$ NPs from BN fillers. However, it is worth

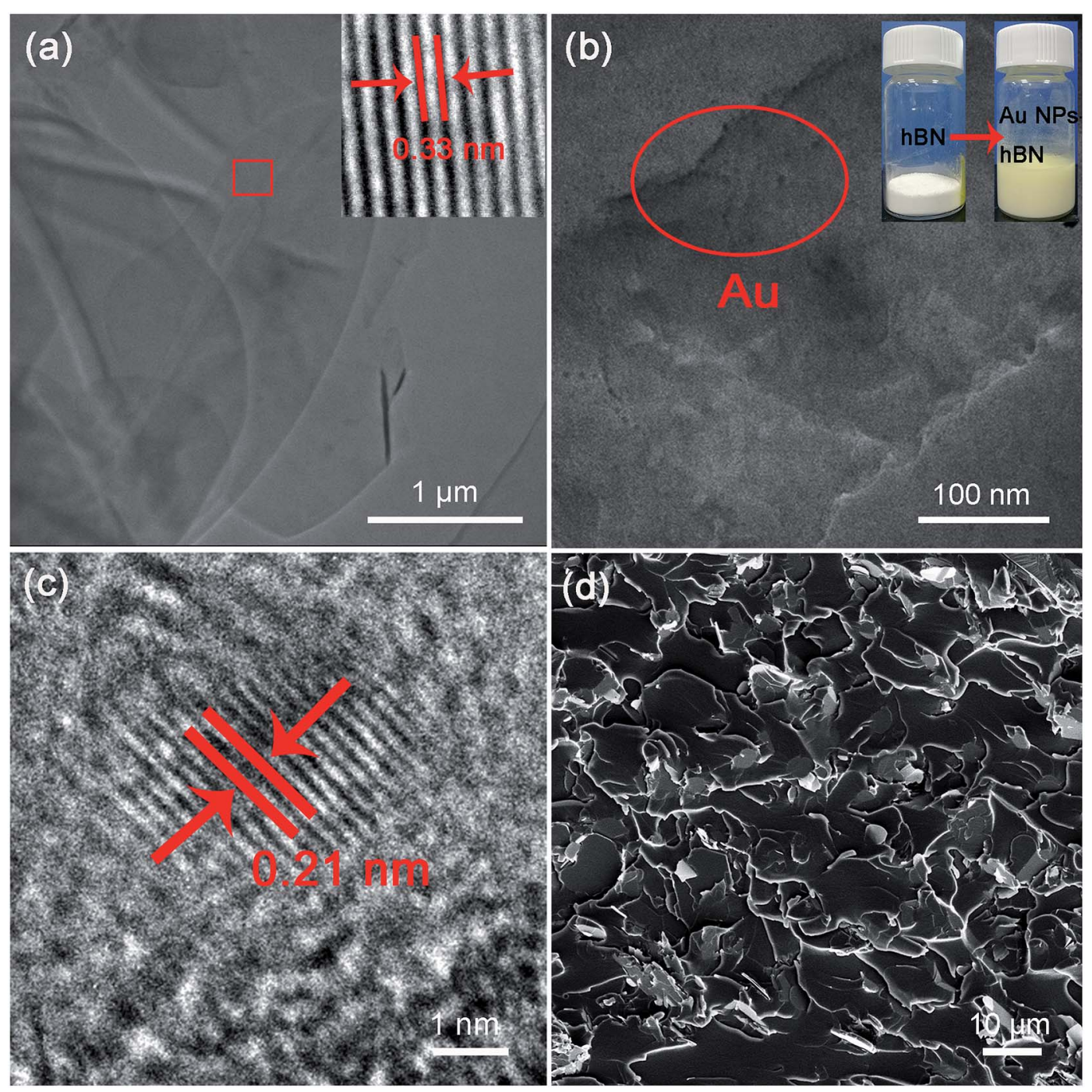

Fig. 8 TEM images of the surface modified h-BN before (a) and after (b) Au NPs decoration, where Au NPs congest at the edges of $h$-BN platelets as marked by red circle in (b), and the insert in (b) is photographs of modified h-BN and Au-h-BN. (c) HRTEM images of h-BN platelets after Au NPs attachment, and a typical crystalline structure of Au is demonstrated with a d-spacing of $0.21 \mathrm{~nm}$. (d) SEM image of the cross-sectional morphology of Au-h-BN/c-BN/EP composites containing 3 vol\% $\mathrm{h}-\mathrm{BN}$ and 6 vol\% c-BN. 
mentioning that the interconnectivity between $\mathrm{h}-\mathrm{BN}$ platelets has been significantly improved in comparison to the h-BN/cBN/EP composites without Au NPs involvement. Here, the Au particles bridge thermal conduction between small h-BN platelets that are located surrounding large c-BN particles to form heat transfer networks within EP matrix and reduce the interfacial resistance. The measured thermal conductivity of $\mathrm{Au}-\mathrm{h}-\mathrm{BN} / \mathrm{c}-\mathrm{BN} / \mathrm{EP}$ composites is $0.656 \mathrm{~W} \mathrm{~m}^{-1} \mathrm{~K}^{-1}$, in contrast to that of EP composites without Au NPs $\left(0.512 \mathrm{~W} \mathrm{~m}^{-1} \mathrm{~K}^{-1}\right)$. In particular, the enhancement in thermal conductivity of h-BN/cBN/EP composites after addition of small amount of Au NPs is induced from the additional heat transfer paths through the edges of $\mathrm{h}$-BN platelets formed by nanoparticles as a thermal bridge.

In addition, the thermal conductivity enhancement is calculated in order to compare EP composites to their neat matrix. Fig. 9a shows the enhancement of Au-h-BN/c-BN/EP composites, h-BN/c-BN/EP composites and h-BN/EP composites in comparison with their neat EP resin. For the h-BN/EP composites, the thermal conductivity is slightly increased by $53.82 \%$ with loading content of h-BN platelets at $3 \mathrm{vol} \%$. The relatively lower increase in thermal conductivity is resultant from the discontinuity in h-BN platelets. Adaptation of hybrid filler system of small h-BN platelets $(5.32 \mu \mathrm{m}, 3 \mathrm{vol} \%)$ and large c-BN particles (59 $\mu \mathrm{m}, 6 \mathrm{vol} \%)$ leads to thermal conductivity increase up to $128 \%$ for $\mathrm{h}-\mathrm{BN} / \mathrm{c}-\mathrm{BN} / \mathrm{EP}$ composites. The large c$\mathrm{BN}$ particles act as skeleton within the polymer matrix, and small h-BN platelets incline to locate nearby the c-BN surfaces.
Such arrangement of hybrid filler system with different size and shape is beneficial to form thermal conduction paths effectively and consequently increase the thermal property. Moreover, the EP composites exhibit dramatic enhancement of $237 \%$ after further addition of small amount of Au NPs to the EP composites containing the hybrid fillers. Such significant enhancement of the Au-h-BN/c-BN/EP composites can be attributed to the improved interconnection between h-BN platelets and reduced interfacial thermal resistance induced by Au NPs.

In order to test the thermal transfer capability of these composites in the real case, heating profiles for $\mathrm{Au}-\mathrm{h}-\mathrm{BN} / \mathrm{c}-\mathrm{BN} /$ EP composites, h-BN/c-BN/EP composites and h-BN/EP composites as a function of temperature from $24{ }^{\circ} \mathrm{C}$ to $58{ }^{\circ} \mathrm{C}$ have been recorded as described in Fig. 9b. Neat EP resin has also been measured as reference. All samples have the same diameter and thickness. It can be seen that after addition of $\mathrm{Au}$ NPs, Au-h-BN/c-BN/EP composites dissipate heat faster than the rest. The temperature profile evolution as a function of time has been recorded using a calibrated IR camera. $\mathrm{EP}, \mathrm{Au}-\mathrm{h}-\mathrm{BN} / \mathrm{c}-$ BN/EP composites, h-BN/c-BN/EP composites and h-BN/EP composites act as the heat sink, which were heated up using the same heater. Fig. $9 \mathrm{c}$ shows the order in which the four samples were tested, and below them is the heating device. As shown in Fig. 9d, infrared thermal images present that the temperature increases gradually as heating time goes. The temperature of $\mathrm{Au}-\mathrm{h}-\mathrm{BN} / \mathrm{c}-\mathrm{BN} / \mathrm{EP}$ composites is the highest among these composites within all the time scale, which

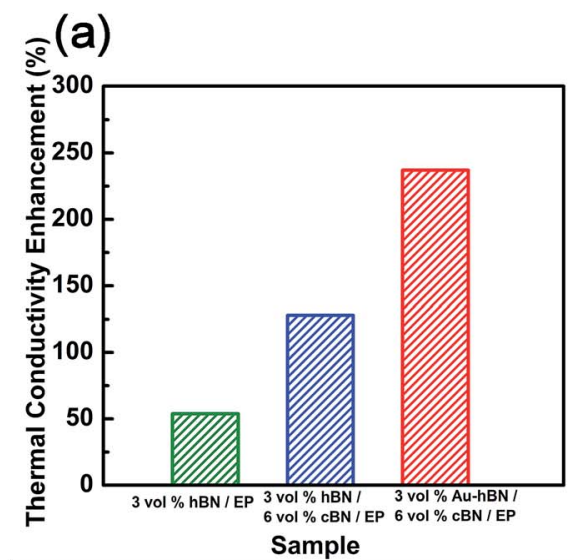

(b)

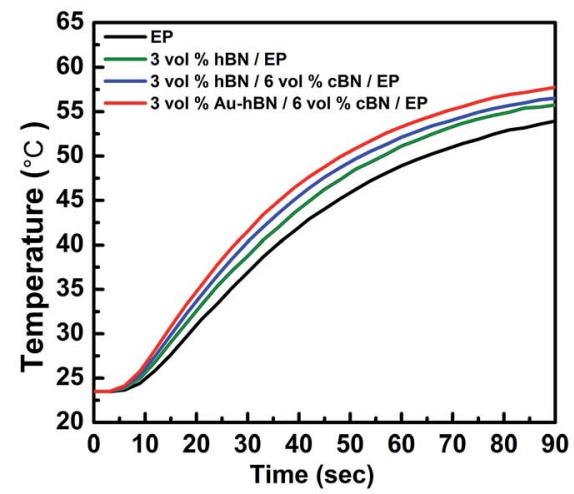

(c)

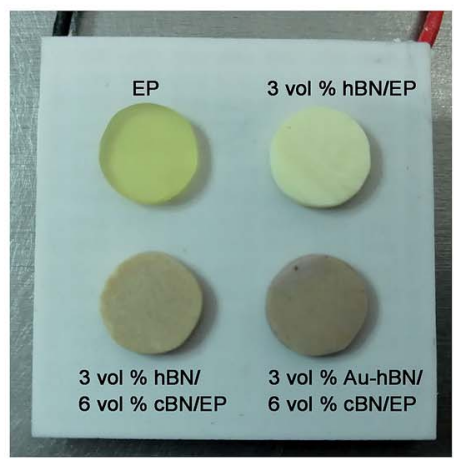

\section{(d)}

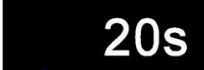

Fig. 9 (a) Thermal conductivity enhancement of $h-B N / E P, h-B N / c-B N / E P$ and Au-h-BN/c-BN/EP composites. (b) Surface temperature variation with heating time. (c) Optical image and (d) infrared thermal images of neat EP resin, $h-B N / E P$ and $h-B N / c-B N / E P$ and Au-h-BN/c-BN/EP composites with heating time at $20 \mathrm{~s}, 40 \mathrm{~s}, 60 \mathrm{~s}$ and $80 \mathrm{~s}$, respectively. 
indicates that $\mathrm{Au}-\mathrm{h}-\mathrm{BN} / \mathrm{c}-\mathrm{BN} / \mathrm{EP}$ composites exhibit better heat transportation performance than the rest in the real case. This is consistent with the higher thermal conductivity obtained in the previous discussion. Meanwhile, it is worth noting that the measured currents through these composites are below the detection limit with applied voltage increased from 0 to $200 \mathrm{~V}$, which indicates excellent electrical insulation. Therefore, it strongly suggests that the present $\mathrm{Au}-\mathrm{h}-\mathrm{BN} / \mathrm{c}-\mathrm{BN} / \mathrm{EP}$ composites are a promising system for application in LED packaging, electronics, aerospace military and other fields.

\section{Conclusions}

In this study, epoxy resins exhibiting excellent thermal conductivity have been prepared using h-BN and c-BN modified as hybrid fillers. The effects of surface modification, filler size and geometry on the thermal conductivity of composites were studied. The results show that surface modification of BN can enhance the thermal conductivity of the composites by improving the dispersibility of BN particles within epoxy matrix. The measured thermal conductivities of the epoxy composites filled with h-BN, c-BN and mixed h-BN/c-BN have been compared with theoretical predications of Agari's model. It strongly suggests that the synergistic effect is beneficial to enhance the thermal conductivity of the polymer composites filled with h-BN platelets and c-BN spherical particles with different sizes at low filler loading content since the use of multi-component of fillers with different types, sizes and shapes preferentially forms thermal conduction channels within the polymer matrix. After linking Au NPs onto h-BN, the thermal conductivity of Au-h-BN/c-BN/EP system is further enhanced for the improved interconnection via Au NPs acting as interfacial bridges.

\section{Conflicts of interest}

There are no conflicts of interest to declare.

\section{Acknowledgements}

The financial supports by the National Natural Science Foundation of China (Grants No. 51572105, 61504046 and 51872113) are specially acknowledged. H. Yin is grateful to the Scientific Research Foundation for the Returned Overseas Chinese Scholars, State Education Ministry. The financial supports from the Scientific Research Foundation for the returned overseas of Jilin Province are also appreciated.

\section{References}

1 Y. H. Zhao, Y. F. Zhang and S. L. Bai, Composites, Part A, 2016, 85, 148-155.

2 D. Lee, S. Lee, S. Byun, K.-W. Paik and S. H. Song, Composites, Part A, 2018, 107, 217-223.

3 C. Yu, J. Zhang, W. Tian, X. Fan and Y. Yao, RSC Adv., 2018, 8, 21948-21967.
4 H. Y. Chen, V. V. Ginzburg, J. Yang, Y. F. Yang, W. Liu, Y. Huang, L. B. Du and B. Chen, Prog. Polym. Sci., 2016, 59, 41-85.

5 H. Im and J. Kim, Carbon, 2012, 50, 5429-5440.

6 Y. M. Xue, X. Zhou, T. Z. Zhan, B. Z. Jiang, Q. S. Guo, X. W. Fu, K. Shimamura, Y. B. Xu, T. Mori, P. C. Dai, Y. Bando, C. C. Tang and D. Golberg, Adv. Funct. Mater., 2018, 28, 1801205.

7 X. Y. Huang, C. Y. Zhi, P. K. Jiang, D. Golberg, Y. Bando and T. Tanaka, Adv. Funct. Mater., 2013, 23, 1824-1831.

8 J. Chen, X. Y. Huang, B. Sun, Y. X. Wang, Y. K. Zhu and P. K. Jiang, ACS Appl. Mater. Interfaces, 2017, 9, 30909-30917.

9 L. C. Guo, Z. Y. Zhang, R. Y. Kang, Y. P. Chen, X. Hou, Y. M. Wu, M. G. Wang, B. Wang, J. F. Cui, N. Jiang, C. T. Lin and J. H. Yu, RSC Adv., 2018, 8, 12337-12343.

10 Y. Hu, G. P. Du and N. Chen, Compos. Sci. Technol., 2016, 124, 36-43.

11 L. J. Fang, C. Wu, R. Qian, L. Y. Xie, K. Yang and P. K. Jiang, RSC Adv., 2014, 4, 21010-21017.

12 Y.-K. Kim, J.-Y. Chung, J.-G. Lee, Y.-K. Baek and P.-W. Shin, Composites, Part A, 2017, 98, 184-191.

13 J.-P. Hong, S.-W. Yoon, T. Hwang, J.-S. Oh, S.-C. Hong, Y. Lee and J.-D. Nam, Thermochim. Acta, 2012, 537, 70-75.

14 Z. Q. Shi, M. Radwan, S. Kirihara, Y. Miyamoto and Z. H. Jin, Appl. Phys. Lett., 2009, 95, 224104.

15 T. Morishita, M. Matsushita, Y. Katagiri and K. Fukumori, J. Mater. Chem., 2011, 21, 5610-5614.

16 A. A. Balandin, Nat. Mater., 2011, 10, 569-581.

17 W. L. Song, W. Wang, L. M. Veca, C. Y. Kong, M. S. Cao, P. Wang, M. J. Meziani, H. J. Qian, G. E. LeCroy, L. Cao and Y. P. Sun, J. Mater. Chem., 2012, 22, 17133-17139.

18 A. K. Singh, B. P. Panda, S. Mohanty, S. K. Nayak and M. K. Gupta, Polym. Adv. Technol., 2017, 28, 1851-1864.

19 L. Jarosinski, A. Rybak, K. Gaska, G. Kmita, R. Porebska and C. Kapusta, Mater. Sci.-Pol., 2017, 35, 382-389.

20 Y. Wu, Y. Xue, S. Qin, D. Liu, X. Wang, X. Hu, J. Li, X. Wang, Y. Bando, D. Golberg, Y. Chen, Y. Gogotsi and W. Lei, ACS Appl. Mater. Interfaces, 2017, 9, 43163-43170.

21 D. S. Muratov, D. V. Kuznetsov, I. A. Il'inykh, I. N. Burmistrov and I. N. Mazov, Compos. Sci. Technol., 2015, 111, 40-43.

22 K. Uetani, S. Ata, S. Tomonoh, T. Yamada, M. Yumura and K. Hata, Adv. Mater., 2014, 26, 5857-5862.

23 N. Yang, C. Xu, J. Hou, Y. M. Yao, Q. X. Zhang, M. E. Grami, L. Q. He, N. Y. Wang and X. W. Qu, RSC Adv., 2016, 6, 1827918287.

24 Z. H. Yu, X. Wang, H. Y. Bian, L. Jiao, W. B. Wu and H. Q. Dai, PLoS One, 2018, 13, e0200842.

25 Z. Y. Lin, Y. Liu, S. Raghavan, K.-s. Moon, S. K. Sitaraman and C.-p. Wong, ACS Appl. Mater. Interfaces, 2013, 5, 76337640.

26 H. Guo, X. Li, B. A. Li, J. X. Wang and S. C. Wang, Mater. Des., 2017, 114, 355-363.

27 X. Yang, X. Y. Yu, K. Naito, H. L. Ding, X. W. Qu and Q. X. Zhang, J. Nanosci. Nanotechnol., 2018, 18, 3291-3298.

28 Y. Li, G. J. Xu, Y. Q. Guo, T. B. Ma, X. Zhong, Q. Y. Zhang and J. W. Gu, Composites, Part A, 2018, 107, 570-578. 
29 T. Huang, X. L. Zeng, Y. M. Yao, R. Sun, F. L. Meng, J. B. Xu and C. P. Wong, RSC Adv., 2016, 6, 35847-35854.

30 L. B. Shao, L. Y. Shi, X. H. Li, N. Song and P. Ding, Compos. Sci. Technol., 2016, 135, 83-91.

31 L. Fu, T. Wang, J. H. Yu, W. Dai, H. Y. Sun, Z. D. Liu, R. Sun, N. Jiang, A. M. Yu and C. T. Lin, 2D Mater., 2017, 4, 025047.

32 Z. G. Li, W. J. Wu, H. Chen, Z. H. Zhu, Y. S. Wang and Y. Zhang, RSC Adv., 2013, 3, 6417-6428.

33 K. Q. Zhou, J. J. Liu, Y. Q. Shi, S. H. Jiang, D. Wang, Y. Hu and Z. Gui, ACS Appl. Mater. Interfaces, 2015, 7, 6070-6081.

34 G. Pan, Y. Yao, X. Zeng, J. Sun, J. Hu, R. Sun, J. B. Xu and C. P. Wong, ACS Appl. Mater. Interfaces, 2017, 9, 3300133010.

35 T. L. Li and S. L. C. Hsu, J. Phys. Chem. B, 2010, 114, 68256829.

36 Q. H. Weng, X. B. Wang, X. Wang, Y. Bando and D. Golberg, Chem. Soc. Rev., 2016, 45, 3989-4012.

37 L. Chen, Y. Y. Sun, H. F. Xu, S. J. He, G. S. Wei, X. Z. Du and J. Lin, Compos. Sci. Technol., 2016, 122, 42-49.

38 X. T. Luo, G. J. Yang and C. J. Li, Surf. Coat. Technol., 2011, 205, 4808-4813.

39 K. C. Yung and H. Liem, J. Appl. Polym. Sci., 2007, 106, 35873591.

40 Q. H. Weng, X. B. Wang, X. Wang, Y. Bando and D. Golberg, Chem. Soc. Rev., 2016, 45, 3989-4012.

41 Y. L. Wang, L. S. Xu, Z. Yang, H. Xie, P. Q. Jiang, J. Q. Dai, W. Luo, Y. G. Yao, E. Hitz, R. G. Yang, B. Yang and L. B. Hu, Nanoscale, 2017, 10, 167-173.
42 J. W. Gu, Q. Y. Zhang, J. Dang and C. Xie, Polym. Adv. Technol., 2012, 23, 1025-1028.

43 I. Jang, K.-H. Shin, I. Yang, H. Kim, J. Kim, W.-H. Kim, S.-W. Jeon and J.-P. Kim, Colloids Surf., A, 2017, 518, 64-72.

44 S. Kemaloglu, G. Ozkoc and A. Aytac, Thermochim. Acta, 2010, 499, 40-47.

45 S. Diaham, F. Saysouk, M.-L. Locatelli, B. Belkerk, Y. Scudeller, R. Chiriac, F. Toche and V. Salles, J. Appl. Polym. Sci., 2015, 132, 42461.

46 Z. B. Wang, T. Iizuka, M. Kozako, Y. Ohki and T. Tanaka, IEEE Trans. Dielectr. Electr. Insul., 2011, 18, 1963-1972.

47 W. Han, Y. Bai, S. Liu, C. Ge, L. Wang, Z. Ma, Y. Yang and X. Zhang, Composites, Part A, 2017, 102, 218-227.

48 W. Gao, Y. Zhao, H. Yin and H. D. Li, Nanoscale, 2017, 9, 13004-13013.

49 B. Yu, W. Y. Xing, W. W. Guo, S. L. Qiu, X. Wang, S. Lo and Y. Hu, J. Mater. Chem. A, 2016, 4, 7330-7340.

50 T. Huang, X. L. Zeng, Y. M. Yao, R. Sun, F. L. Meng, J. B. Xu and C. P. Wong, RSC Adv., 2017, 7, 23355-23362.

51 Y. Agari, M. Tanaka and S. Nagai, J. Appl. Polym. Sci., 1987, 34, 1429-1437.

52 S. M. Kong, M. Mariatti and J. J. C. Busfield, J. Reinf. Plast. Compos., 2011, 30, 1087-1096.

53 C. C. Furnas, Reports of Investigations, 1928, pp. 1-10.

54 J. V. e. Milewski and H. S. e. Katz, Handbook of reinforcements for plastics, 1987.

55 D. de las Heras and M. Schmidt, Philos. Trans. R. Soc., A, 2013, 371, 20120259. 